\title{
Yapay Sinir Ağı ve Box-Jenkins Modeli ile Yazıcı Sarf Malzemelerinin Analiz ve Modellenmesi: Irak Örneği
}

\author{
Ban ALMAHMUD', Mehmet ALBAYRAK²
}

${ }^{1}$ Süleyman Demirel Üniversitesi, Fen Bilimleri Enstitüsü, Bilgisayar Müh. EABD, Isparta, Türkiye

2 Isparta Uygulamalı Bilimler Üniversitesi, Uzaktan Eğitim MYO, Bilgisayar Teknolojileri Böl., Isparta, Türkiye

(Alınış / Received: 25.12.2019, Kabul / Accepted: 17.02.2020)

Anahtar Kelimeler

Yapay Sinir Ağl, Box-Jenkins Modeli, Yazıcı Sarf Malzemeleri.
Özet: Bu çalışmada, Irak'ta Ocak-Aralık 2018 sürecinde toplanan verilerden, yazıcı sarf malzeme satışları öngörüsünde bulunabilmek amacıyla, Box-Jenkins (B-J) ve Yapay Sinir Ağları (YSA) yöntemleri kullanılarak analizler ve ileriye dönük satış tahmini için modellemeler yapılmıştır. Toplam 132 gözlemden oluşan, Ocak 2008 ile Aralık 2018 arasındaki süreçte, yazıcı sarf malzemelerinin satıș miktarları ele alınarak zaman serisi ile analiz edilmiștir. Çalışmada B-J metodu uygulanarak veri temsili için Otoregresif ve Bütünleşik Otoregresif Hareketli Ortalama (ARIMA Autoregressive Integrated Moving Average) yöntemleri kullanılmıştır. Analizler sonucunda oluşturulan farklı modellerin arasında en uygun modelin ARIMA $(0,1,0)(0,0,1)$ olduğu sonucuna varılmıştır. Bu modelin seçilme nedeni, öngörü doğruluğu kriteri sayılan Hata Karelerinin Ortalama Kökü (RMSE - Root Mean Square Error) ve Ortalama Mutlak Hata (MAPE - Mean Absolute Percentage Error) değerleridir. YSA ile modelleme yapıldığında ise farklı modeller test edilmiş, kurulan modellerin içinde en uygun modelin çok katmanlı YSA (5.5.1) modelinin olduğunu görülmüştür. Bu iki farklı yöntem arasında RMSE ve MAPE kıstası kullanılarak öngörünün doğruluğu ve performans yönünden karşılaştırma yapılmıştır. B-J ve YSA modelleri kendi arasında kıyaslandığında çok katmanlı YSA modelinin en uygun model olduğu görülmüştür. Bu model ile yazıcı sarf malzeme satışları zaman serisinden yararlanılarak, ileriki yıllar için satıș miktarı değerlerinin tahmini yapılabilmektedir.

\section{Analysis and Modeling of Printer Consumables with Artificial Neural Network and Box-Jenkins Model: The Iraq Case}

\section{Keywords}

Artificial Neural Networks, Box-Jenkins Model, Printing Stuffs.

\begin{abstract}
In this study, Box-Jenkins (B-J) and Artificial Neural Networks (ANN) methods were used to predict the sales of printer consumables from the data collected in the given time period (January-December 2018) in Iraq and future forecasts were made. In the period between January 2008 and December 2018, which consisted of 132 observations, the sales quantities of printer consumables were analyzed and the corresponding time series were analyzed. In the study, B-J method was applied and Autoregressive and Integrated Autoregressive Moving Average (ARIMA) methods were used for data representation. ARIMA $(0,1,0)$ $(0,0,1)$ was the most suitable model among the different models. The reason for selecting this model is the Root Mean Square Error (RMSE) and Mean Absolute Percentage Error (MAPE) values, which are considered predictive accuracy criteria. When modeling with ANN, different models were tested and it was found that the most suitable model among the established models was the multilayer ANN (5.5.1) model. The accuracy and predictability of the predictions were compared using the RMSE and MAPE criteria. When the B-J and ANN models are compared, it is seen that the multi-layered ANN model is the most suitable model. With this model, it is possible to estimate the sales quantity values for the following years by making use of the printer consumable sales time series.
\end{abstract}




\section{Giriş}

Yazıcı sarf malzemeleri, dijital dünyanın hızla gelişmesine rağmen, günlük hayatta fark edilmese bile sıklıkla pek çok alanda halen kullanılmaktadır. Basılı materyal fiyatlarının artmaması adına bu alanda çalışan yatırımcılar yazıcı sarf malzemelerin fiyatını en düşük seviyede tutmaya çalışmaktadırlar.

Ülkelerde yaşanan ekonomik ve politik olayların etkisi ile diğer pek çok malzeme gibi yazıcı sarf malzemelerinin de fiyatı da dalgalanmaya ve yükselmeye maruz kalabilmektedir. $\mathrm{Bu}$ nedenle yatırımcılar, istatistik yöntemler kullanarak yazıcı sarf malzemelerin satış miktarını ve fiyatını tahmin etmeye ihtiyaç duymaktadırlar. Bu çalışmanın ana çıkış noktası da bu konuya dayanmaktadır.

Bu araştırmada, zaman serisi tahmini için, iki tahmin yöntemi kullanılmıștır. Bunlardan ilki geleneksel BoxJenkins modeli; diğeri ise daha modern yöntem olarak anılan YSA modelidir. Uygulama, yazıcı sarf malzeme satış firmalarının zaman serilerine uygulanmıştır. Yazıcı sarf malzemeler ile ilgili çalışmada kullanılan veriler, yazıcı sarf malzemelerin satıcı ve dağıtıcı firmaların kayıtlarından birebir alınmıștır. Veriler Ocak 2008 ile Aralık 2018 sürecinde alınan verilerdir. Veri setinde 132 adet aylık veri grubu kullanılarak, öngörü işlemi gerçekleştirilmiştir.

Akdağ (2015) çalışmasında, ülkeler için büyük bir önem taşıyan enflasyon beklentilerini tahmin etmiştir. Gelişmekte olan ülkeler açısından enflasyon oranının düşük seyretmesi önemli hedeflerden birisidir. Bu nedenle geçmiş verilere bakarak geleceğe yönelik doğru tahminlerde bulunmak önemlidir. Kısa vadeli tahmin çalışmalarında en uygun yöntemlerden birisi zaman serilesidir. Çalışmalarında B-J ve YSA olarak bilinen yöntemlerle enflasyon verisine ait zaman serisi analizi kullanılmış ve sonuçlar karşılaştırmalı olarak sunulmuşlardır [1].

Bluestone (1963) çalışmasında, Broyler Döngüleri' ni tahmin etmek için geleneksel, mevsimsel ayarlama ve veri filtreleme yöntemlerini uygulamıştır. Dönemsel uyum için nüfus sayımı yöntemini kullanarak "iyi tanımlanmış 4 döngü" olarak adlandırdı̆̆ı modeli belirlemiştir [2]. Çalışmalarında kullanılan veriler ile mevsimsel zaman serisi modeli kurmuşlardır. Bu çalışma ile modelleme yapısı bakımından benzerlik göstermektedir.

Cancela (2008) çalışmasında, ortalama 4175 görüntüleme sonucu 1-2-1991 ile 1-2-2006 arasındaki günlük zaman serisi verilerine dayanarak YSA modelleri ve dört ülke için (Almanya, İtalya, Yunanistan ve Portekiz) ARIMA modeli kullanarak döviz kurları arasındaki karşılaştırmayı incelemektedir. Sonucunda YSA modelinin üstün olduğu göstermiş ve tahminde kullanmıştır [3].
Commandeur ve Koopman (2007) çalışmalarında, "Ekonomik ve sosyal alanlarda, gerçek seriler asla durağan değildir, ancak çok farklıdır" ifadesini kullanarak B-J yaklaşımının temelinde sorunlu olduğunu ileri sürmüşlerdir. Böylece araştırmacı, yazarların belirttiği gibi serinin durağanlığa ne kadar yakın olduğunu sorgulamalıdır. Ayrıca B-J'i kullanmak yerine, zaman serisinin durağan olmadığı hallerde, durum alanı yöntemlerini kullanmanın daha iyi olduğunu tartışmaktadırlar [4]. Çalışmalarında kullanılan modelleme yapısı yapılan çalışma ile benzerlik göstermektedir.

Çuhadar (2006) çalışmasında, Ocak 1992 ile Aralık 2005 tarihleri arasında Antalya iline gelen toplam yabancı turist saylarının verisini kullanarak, "Mekanik Tahmin (Naive III), "Hareketli Ortalamalar", Üstel Düzleștirme", "B-J (ARIMA)" ve "YSA" modellerinin tahmin sonuçlarını karşılaştırmaktadır. Bu çalışmada, 2006-2007 yılları için Antalya iline yönelik dış turizm talebinin aylar itibariyle tahmin edilmesi amaçlanmıştır. Sonuç olarak, YSA modellerinin, diğer yöntemlerle kurulan modellere göre daha iyi sonuçlar verdiği görülmektedir [5].

Garg vd. (2016) çalışmalarında, Delhi için Gürültü Kontrol Mühendisliği Enstitüsü'nden Aralık 2013 ile Ağustos 2014 arasındaki dönemde elde edilen günlük verilere dayanarak, Box-Jenkins yöntemine ait farklı modeller ile YSA' nın tahmin yeteneklerini karşılaştırmaktadır. Kullandığı veri setinden hareketle, kurmuş olduğu YSA modelinin uyum sağlama konusunda ARIMA' dan daha iyi performans gösterdiği sonucuna varmıştır [6].

Gao vd. (2017) çalışmalarında, ARIMA ve YSA modellerini, 22 Mart - 14 Temmuz 2010 tarihleri arasındaki zaman serisi verilerine dayanarak Ingiltere Enerji Piyasası için elektrik fiyatlarını modellemiştir. Çalışma, ARIMA modelinin, RMSE ölçeğinin öngörme doğruluğuna göre YSA modeline kiyasla iyi bir sonuç sağladığını göstermiştir [7].

Gerra (1959) çalışmasında, yumurta endüstrisi için temel ekonomik sistemi teşvik ettiğine inanılan bir dizi davranış ilişkileri sunmuştur. Yumurta endüstrisindeki değişkenlerin değerlerini tahmin etmeye yönelik denklemlerin (bir ekonometrik model) kullanılmasıyla, yıllık miktar değişkeni (yerli yumurta tüketimi, çiftliklerde yumurta üretimi, ortalama sayı) için daha iyi tahminler yapıldığını belirtmiştir. Depolama hareketi ve fiyat değişkenleri gibi bazı değişkenler için daha iyi tahminler, en küçük kareler yöntemi ile elde edilmiştir [8]. Çalıșmalarında kullanılan veriler ile mevsimsel zaman serisi modeli kurmuşlardır. $\mathrm{Bu}$ çalışma ile modelleme yapısı bakımından benzerlik göstermektedir.

Hamzaçebi vd. (2009) yaptıkları "Yapay Sinir Ağları ile Türkiye Elektrik Enerjisi Tüketiminin 2010 Yılına Kadar Tahmini" isimli çalışmalarında; YSA, ARIMA ve 
Kısmi Uyarlamalı Tahmin tekniklerini karşılaştırmıştır. Çalışmanın sonucunda YSA' nın diğer metotlardan daha iyi tahmin performansına sahip olduğunu göstermişlerdir [9].

Ighravwe ve Anyaeche (2019) çalışmalarında, Nijerya'nın Apapa limanından toplanan verilere dayanarak B-J ile YSA modellerinin tahmin sonuçları arasında karşılaştırma yapmışlardır. Veri seti olarak geminin limanda ve rıhtımda geçirdiği günler ele alınmıștır. Çalışma, YSA modelinin ARIMA modelinden daha üstün olduğunu göstermiştir [10].

Karaboga (2007) çalışmasında, Kanyakumari Bölgesi' ne ait seçilmiş malların fiyatlarını tahmin etmek için sadece zaman serisi modelleri kullanmıştır [11]. Çalışmalarında kullanılan veriler ile zaman serisi modeli kurmuşlardır. Bu çalışma ile modelleme yapısı bakımından benzerlik göstermektedir.

Leuthold vd. (1970) çalışmalarında, günlük domuz eti fiyatının tahmin edilmesine yönelik yaptıkları çalışmada, farklı tahmin yaklaşımlarının doğruluğunu karşılaştırmak için Theil'in Eşitsizlik Katsayısını kullanılmıştır. Fiyat tahminleri için; ekonometrik model, rassal yürüyüş modeli ve ortalama model kullanılmıştır. Arz tahminleri için ekonometrik model, rassal yürüyüş modeli, ortalama model ve zaman serisi modelleri karşılaştırılmıştır. Zaman serileri modellemesi için gerekli olan verilerin tahmin edilecek olan değişkenle ilgili veriler olduğu belirlenmiştir. Ayrıca ekonometrik modeller için ise hem regresör hem de regresyonda verilere ihtiyaç duyulduğu sonucuna varmışlardır. Ayrıca, ikincisinin kullanımında biraz daha büyük hata yapma maliyeti, bir ekonometrik modelin oluşturulmasında ve verilerin toplanmasında ek maliyetten daha az olacağını göstermiştir [12]. Çalışmalarında kullanılan veriler ile zaman serisi modeli kurmuşlardır. Bu çalışma ile modelleme yapısı bakımından benzerlik göstermektedir.

Montanes vd. (2002) çalışmalarında, nükleer enerji verileri ile yaptıkları analiz sonucunda, YSA modelinin daha iyi tahmin performansına sahip olduğu ve ARIMA modellerinin zaman serisindeki sistematik değişiklikleri başarılı bir şekilde tahmin etmediği sonucuna varmışlardır [13].

Nury vd. (2017) çalışmalarında, Kuzeydoğu Bangladeş'in sıcaklık verilerine dayanarak, BoxJenkins Modelleri ile YSA' nın tahmin yeteneklerinin arasındaki karşılaştırmayı incelemiştir. Bu modelleme için, 1957-2000 yılları arasındaki eğitim verileri ve performanslarını tahmin etmek için de 2001-2012 yılları arasındaki veri grubundan oluşan iki veri kümesi kullanmıştır. Sonuçlar B-J modellerinden biri olan ARIMA ile kurulan modelin, YSA modelinden daha iyi performans ortaya çıkarmıştır [14].
Pandey (2019) çalışmasında, Ocak 2007 ile Aralık 2016 tarihleri arasında Hindistan'daki borsa günlük verilerine dayanarak B-J ve YSA modellerinin tahmin sonuçlarını karşılaştırmaktadır. Sonuç olarak, YSA modelinin ARIMA modelinden daha üstün olduğunu göstermiştir [15].

Safi (2016) çalışmasında, 2000-2014 dönemi için Filistin Devleti'nin GSYIH verilerine dayanarak, BoxJenkins modelleri ile YSA tahmin yeteneklerini karşılaştırmaktadır. Çalışma sonucunda, YSA modelinin ARIMA modelinin performansından daha üstün olduğunu ortaya koymuştur [16].

Suits (1962) çalışmasında, ABD ekonomisinde politika analizi için ekonometrik bir modeli sunarken, bu modelin bir tahmin aracl olarak etkilerini araştırmıştır. Çalışmada; ekonometrik modellerin genel doğası ile son derece sadeleștirilmiş șematik bir örnek kullanarak, bir modelle tahminlerin nasıl yapıldığını göstermiştir. Ayrıca bir modelin ek bilgi ve muhakeme kararının verilmesine nasıl izin verileceğini ve uzun vadede nasıl çalıştığını göstermiştir [17]. Çalışmalarında kullanılan verilerin ekonometrik model olması ve modelleme yapısı bakımından bu çalışma ile benzerlik göstermektedir.

Schmitz ve Watts (1970) çalışmalarında; Amerika Birleşik Devletleri, Kanada, Avusturya ve Arjantin'deki buğday verimlerini tahmin etmek için parametrik modelleme kullanmışlardır. $\mathrm{Bu}$ yaklaşımın özü, verilerin, hareketli ortalama ve otoregresif süreç biçimindeki rastgele bileşenlerin tahminini tanımlamak için kullanılmasıdır. Amerika Birleşik Devletleri ve Kanada' da verimi tahmin etmek için üssel düzeltme kullanılmıştır. Ayrıca parametrik modelleme ile üstel düzeltme arasındaki tahmin doğruluklarını karşılaştırılmıştır [18]. Çalışmalarında kullanılan verilere etki eden faktörler ve tahmin etme yöntemi açısından benzerlik göstermektedir.

Tobin ve Arthur (1964) çalışmalarında, Broyler piliç fiyatları için altı aylık bir geçiş filtresi (Basit Hareketli Ortalama) ve kuluçka tedarik sürülerinde on iki aylık süreç kullanmıştır. Elde edilen filtrelenmiş seri, her iki seri için yaklaşık 30 aylık döngüleri ortaya çıkarmıştır. 30 aylık döngünün iki serisinin zirveleri arasında 12 ila 18 aylık bir zaman farkı bulunmaktadır. Benzer bulgular Gross ve Ray tarafından da gözlemlenmiștir [19]. Çalışmalarında kullanılan veriler ile zaman serisi modeli kurmuşlardır. Bu çalışma ile modelleme yapısı bakımından benzerlik göstermektedir.

Ture ve Kurt (2006) çalışmalarında, hepatit A virüsü vakalarının öngörüsü için çok katmanlı, radyal tabanlı ve zaman gecikmeli olmak üzere üç farklı YSA ile ARIMA modellerini kullanmışlardır. 13 yıllık zaman serilerinin analizi sonucu olarak, çok katmanlı YSA modelinin diğer yöntemlerden daha iyi tahmin performansına sahip olduğunu göstermişlerdir [20]. 
YSA ve Box-Jenkins (B-J) metodunu kullanarak gerçekleştirilmiş birçok zaman serisi çalışması literatürde yer almaktadır. Bu bölümde, bu konuyla ilgili daha önceki çalışmalar sunulmuştur.

\section{Materyal ve Metot}

Tahmin modellerini oluşturmak için birçok yöntem vardır. Ancak bu modellerden, farklı alanlarda en sık kullanılan yöntemlerden biri de zaman serisi analiz yöntemidir. Zaman serisi analiz yöntemi; aralarında herhangi bir iç bağlantı olmayan, kalıntı (residual) oranını en düşük seviyede bırakan verilerin doğasına uygun matematiksel bir modelin oluşturulmasına dayanmaktadır [21].

\subsection{Box-Jenkins (B-J) Metodolojisi}

B-J modeli, modele adını veren bilim insanları tarafından, 1970 yılında yayımlanan çalışmalarında ortaya koydukları analiz metodudur. En güvenilir modern analiz ürünlerinden birisi sayılabilen zaman serisi, modern analiz metodu olarak kabul edilmiştir. B-J metodolojisi kullanılarak zaman serileri modellerinin oluşturulması dört ayrı süreçte gerçekleştirilmiştir. Bunlar; verilerin incelenerek uygun modelin belirleme süreci, modelin tahmini, modelin teşhisi ve son olarak da uygun bulunan model ile öngörü sürecidir [22].

\subsubsection{Model Belirleme Süreci}

Zaman serisi modelleri belirlenmesi süreci, zaman serileri modellerinin kurulmasında en önemli aşamadır. $\mathrm{Bu}$ algoritma sürecinin ilk aşamanın temelini 1976 yılında iki bilim insanı olan Box ve Jenkins oluşturmuştur. Belirleme süreci öncesinde ise verilerin hazırlanması aşaması gelir. Verilerden tahmin sonuçlarının elde edilmesi, tam ve kısmi otokorelasyon bağlantılarının gözlemleri sırasında verilerin düzenli olması halinde, tanınmaya veya belirlenmeye hazır anlamına gelir. Serinin ortalaması ve varyansında düzensizliklerin bulunması halinde ise, bu düzensizliğin ortalamada giderilmesi için birinci varyansları $(\mathrm{d}=1)$ alınır. $\mathrm{Bu}$ işleme rağmen düzensizliğin giderilmemesi halinde de ikinci varyans $(d=2)$ alınır. Genellikle birinci veya ikinci varyans değerleri ile seri düzenli hale gelir. Düzensizliğin devam etmesi durumunda ise bu düzensizlik, verilerin düzenlenmesi ile giderilebilir. Zaman serisinin istikrara (düzene) kavuşmasından sonra model belirleme aşamasına geçilir. Bu așama zaman serisini oluşturan veriler ile başka bilgilerin kullanılmasına geçilmesi anlamına gelir. Burada asıl amaç ARIMA genel doğrusal modelinin kurulabilmesi için gerekli olan parametrelerinin elde edilmesidir [22].

Modeli ve derecesini belirlemede kullanılan iki fonksiyon ise otokorelasyon (ACF - Autocorrelation Function) ile kısmi otokorelasyon (PACF - Partial Autocorrelation Function) fonksiyonlarıdır. Bu iki fonksiyonun grafiği çizilerek otokorelasyon ve kısmi otokorelasyon işlemlerinin, bu fonksiyonlar teorik davranışları ile uyumu sağlar [23].

\subsubsection{Modelin Tahmini}

Modelin tahmin süreci, zaman serilerinin incelenmesi ve analizinin ikinci aşamasıdır. Bu aşama öncesinde zaman serisi için uygun bir modelin belirlenmesi gerekmektedir. Kurulması istenilen modelin ana amacının gerçekleşmesi için de doğru öngörünün oluşturulması gerekmektedir. Bu oluşturma işlemi sırasında da öngörünün tahmin kalitesi ile ele alınan zaman serisine uygunluğunun incelenmesi gerekmektedir. Model tahminin düzgün yapılması için birçok metot bulunmaktadır. Bunların en önemlileri ise:

- Olağan en küçük kareler metodu (OLS - Ordinary Least Squares), yapılan tahmin için, hata karelerinin azaltılması ve minimum düzeye getirilmesi esasına dayanmaktadır.

- Maksimum olasılıklar metodu (MLE- Maximum Likelihood Estimation), tahmin edilmesi düşünülen modelin sıralanmış değerlerinin belirlenmesi ve hata karelerini en aza indirgeyen olasılık fonksiyonun büyütülmesi esasına dayanmaktadır [24].

\subsubsection{Modelin Teşhisi}

Birinci aşamada oluşturulan zaman serisi modeli; modelin verilerini, genel yapısını ve rastgele değişkenleri $(\mathrm{t})$ oluşturan rastgele işlemlere dair önemli teorik varsayımlara dayanır. Model taslağını tanıma ve özelliklerinin tahmin edilmesinden sonra, modelin değerlendirilmesi yapılarak bu teorik varsayımlara uygun olup olmadığına karar verilir. Karar aşamasında ise birçok test ve analizler yapılır. Bunlar; durağanlık analizi, yansıtma analizi ve kalıntıların analizidir. Kalıntıların grafiğe çizilmesi ile birlikte; istatiksel testler ile ortaya çıkması mümkün olmayan, aykırı veriler gibi kalıntıların ana görüntüsü ortaya çıkar [25].

Aynı zamanda kalıntıların, otokorelasyon analizleri ile modelin uygun olup veya olmadığ ile bu modelin zaman serisi verilerini temsil etme yeterliliğinin bulunup bulunmadığı test edilir [26]. Böylece denklem 1 'de verilen yokluk hipotezini (Ljung-Box(Q)) test etmek için kullanılan seri, bağımsızlık testine dayanır.

$H_{0}: \rho_{1}=\rho_{2}=\cdots \rho_{s}=0$

$\mathrm{Bu}$ metot kalıntılara dair otoregresif fonksiyonlara dayalı olup, (Q) testinin istatistiksel matematik formülü de denklem 2'de verilmiştir:

$Q(s)=n(n+2) \sum_{k=t}^{s}\left(\frac{1}{n}-k\right) r_{k}^{2}$ 
Q Testi ölçütü X2 dağılımını izlemekte ve $Q(s) \sim x_{((s-m), a)}^{2}$ olur.

Burada, m tahmini katsayl adedi, $\mathrm{k}$ toplam sapma adedi ve s mümkün olan maksimum sapmadır.

\subsection{Yapay Sinir Ağları}

Aktif bir uygulama alanı olan zaman serisi kanalıyla geleceği tahmin uygulaması sırasında YSA modelinin kullanımı oldukça yaygındır. Zaman serileri ile öngörü metodunun kullanıldığı ve genel olarak zaman serileri analizi yöntemleri olarak bilinen klasik yöntemlerden olan; hareketli ortalama, sigmoid fonksiyonu ve B-J modelleri gibi birçok uygulama vardır. Bu klasik istatistik uygulamalarına alternatif veya benzer bir metot olarak YSA tekniği kullanılmaya başlanmıştır. Öngörü uygulamalarında kullanılan YSA modelleri klasik öngörü uygulamaları ile rekabet ederek elde ettiği sonuçların güvenilirliği ve doğruluğu ile birçok durumda daha da üstünlük kazanmıştır. YSA modeli zaman serileri içerisinde öngörü yeteneğini ortaya koyarak çizgisel olmayan verileri işlemede bir hayli yetenekli olduğunu kanıtlamıștır. Bütün veri serileri doğrudan çizgisel olmayan ilişkiler ortaya koymaktadır. Bu durumda YSA modeli klasik öngörü metotlarına kıyasla üstünlük sağlamaktadır. Zira birçok klasik öngörü metodu çizgisel veriler ile işlem yapmaktadır.

Şekil 1'de ağları bir grup işlem biriminden oluşan nöron öğeleri gösterilmektedir.

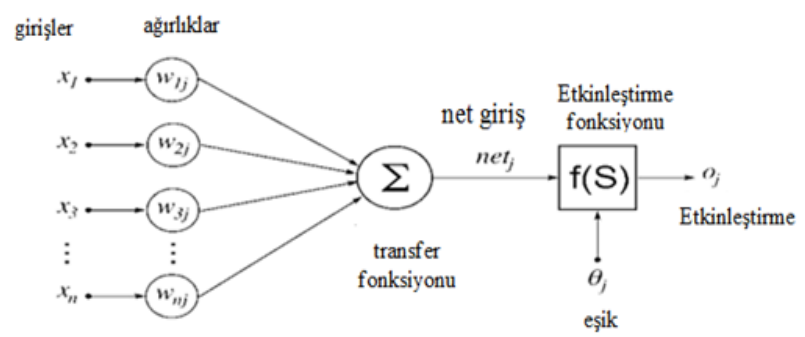

Şekil 1. YSA Modeli [27].

Girdi birimleri kendi başına girdi katmanı denilen katmanı oluşturur. İşlem birimleri ise bu girdileri işleme katılmasını sağlar ve sonuçları ortaya çıkarır. $\mathrm{Bu}$ katmanların arasında, ilk katman ile sonrasında gelen katmanla bağlantıyı sağlayan ara bağlantı elemanları bulunmaktadır. Bunların vasıtasıyla da bu ara bağlantı elemanlarının ağırlıkları kontrol altına alınır. Ağ içerisinde girdi katmanından sadece bir adet bulunmakla birlikte, birden çok işleme katmanı bulunmaktadır [27].

\subsection{Modeller Arası Tercih Kriterleri}

Çalışmada ele alınan iki yöntemin tahmin başarısını ölçmek için, ortalama karesel hata (MSE), hata karelerinin ortalama kökü (RMSE), ortalama mutlak yüzde hata (MAPE), Akaike bilgi kriteri (AIC) ve Bayesian bilgi kriteri (BIC) kullanılmıştır. Bu kriterlerin hesaplanabilmesi için kullanılan formüller aşağıda verilmiștir.

$$
\begin{aligned}
& M S E=\frac{1}{n} \sum_{t=1}^{n} \quad\left(y_{t}-\hat{y}_{t}\right)^{2} \\
& R M S E=\sqrt{\frac{1}{n} \sum_{t=1}^{n} \quad\left(y_{t}-\hat{y}_{t}\right)^{2}} \\
& M A P E=\left(\sum_{t=1}^{n} \quad\left|\frac{y_{t}-\widehat{y} t}{y_{t}}\right| \frac{100}{n}\right) \\
& A I C(M)=n \ln \sigma_{\alpha}^{2}+2 M
\end{aligned}
$$

$$
B I C(M)=n \ln \sigma_{\varepsilon}^{2}-(n-M) \ln \left(1-\frac{M}{n}\right)+M \ln (n)+M \ln \left[\frac{\frac{\sigma_{y}^{2}}{\sigma_{\varepsilon}^{2}}-1}{M}\right](7)
$$

Burada $y_{t}$ gerçekleșen değeri, $\hat{y}_{t}$ öngörülen değeri, $n$ öngörülen dönem sayısını, $M$ modelin seviyesi, $\sigma_{y}^{2}$ seri farkı miktarını ifade etmektedir. $\sigma^{2}$ hata farkı miktarı olup $\sigma^{2}=\sum_{t=1}^{n}\left(y_{t}-\hat{y}_{t}\right) /(n-p)$ formülü ile ifade edilmektedir. Yukarıdaki formüller ile elde edilen kriter değerleri incelendiğinde, en düșük kriter değerine karşılık gelen model kullanılır.

\section{Bulgular}

Çalışmada elde edilen/kullanılan veriler, aylık olarak toplanmış ve toplamda 132 gözlemden oluşan, Ocak 2008 ile Aralık 2018 ayları arasında elde edilen verilerdir. Şekil 2'de elde edilen zaman serisinin grafiği gösterilmektedir. Şekil 2' den anlaşıldığı üzere zaman serisinin davranışının dönemsel olduğu ve ortalamada durağan olmadığı görülmektedir.

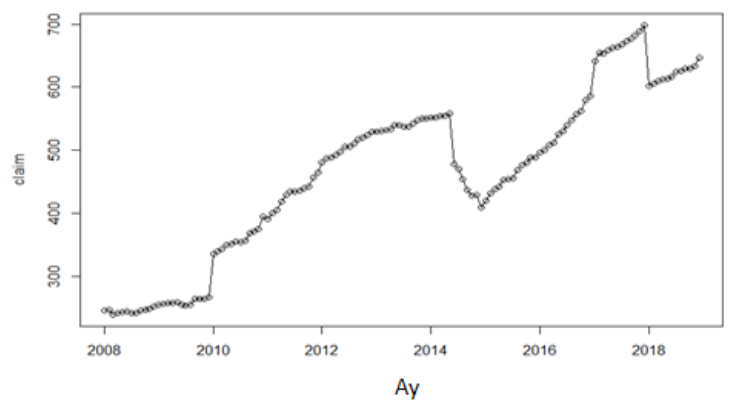

Şekil 2. Aylık Yazıcı Sarf Malzeme Satışları Miktarı Zaman Serisi Grafiği

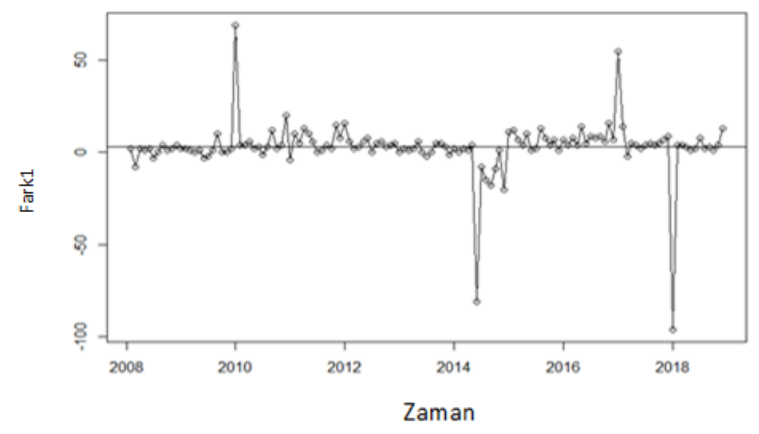

Şekil 3. Birinci Dönemsel Farktan Sonra Yazıcı Sarf Malzeme Satışları Zaman Serisi 
Şekil 3' te zaman serisinin birinci dönemsel farkı gösterilmiştir. Şekil 3' de görüldüğü üzere, zaman serisi birinci fark işlemi sonrasında durağan hale gelmektedir. Serinin durağanlaştrrılması için gerekli olan farklılığın minimum $\mathrm{d}=1$ değeri elde edilmiştir.

\subsection{Box ve Jenkins Metodu Kullanılarak ARIMA Modelinin Olușturulması}

Durağan bir zaman serisine ulaşıldıktan sonraki adımda, zaman serisine uygun dönemsel modelin belirlenmesine geçilir. Çizelge 1' de açıklandığı gibi (RMSE, MAPE, MASE, AIC, BIC) ölçütlerine dayanılarak birden fazla model ele alınmıştır.

Çizelge 1. Zaman Serisi için En Uygun Dönemsel Modelin Seçimi

\begin{tabular}{|c|c|c|c|c|c|}
\hline Model & RMSE & MAPE & MASE & AIC & BIC \\
\hline ARIMA $(0,1,0)(0,0,1)$ & 14.31712 & 1.451328 & 0.093595 & 1076.64 & 1085.26 \\
\hline ARIMA $(0,1,0)(0,0,0)$ & 14.92483 & 1.556303 & 0.103801 & 1082.95 & 1085.83 \\
\hline ARIMA $(0,1,0)(1,0,0)$ & 14.80679 & 1.642465 & 0.110088 & 1083.09 & 1088.84 \\
\hline ARIMA $(0,1,0)(1,0,1)$ & 14.78277 & 1.634145 & 0.109331 & 1084.78 & 1093.41 \\
\hline
\end{tabular}

Çizelge 1' de görüldüğü üzere en uygun modelin ARIMA $(0,1,0)(0,0,1)$ modeli olduğudur. Bu model en düşük istatistiksel ölçüt değerlerini (RMSE, MAPE, MASE, AIC, BIC) içermektedir. Dolayısıyla öngörü için önerilen en uygun modelin ARIMA $(0,1,0)(0,0,1)$ modeli olduğu görülmektedir.

\subsection{Yapay Sinir Ağları Modelinin Oluşturulması}

YSA zaman serilerinin analizi için kullanılan en uygun ve kolay yöntemlerden biridir. Burada verileri herhangi bir ișleme tabi tutmadan kullanmak mümkündür. Araștırmacılar, zaman serilerinin öngörülerinden değişik ağları kullanmış fakat bunların içerisinde bu çalışmada da kullanılan "Çok Katmanlı Sinir Ağı (MLP- Multi Layer Perceptron)" modeli en yaygın kullanıma sahip olan sinir ağı modeli olmuştur.

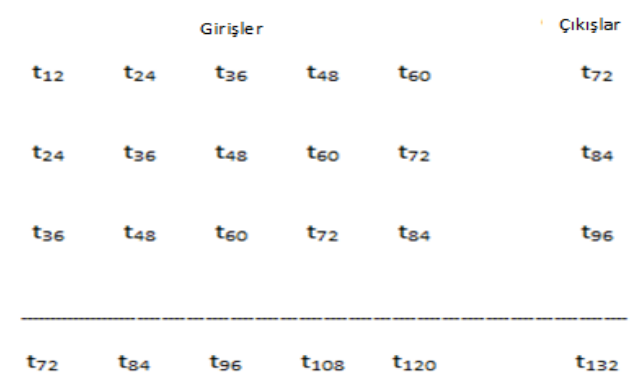

Şekil 4. YSA Modelinde Kullanılan Veri Seti

Verilere YSA modeli uygulanmadan önce, çalıșmada kullanılan metotlardan biri olan zaman serisi metodu ile bazı bölümlere ayrılmıștır. Zira yazıcı sarf malzeme satışlarının zaman serisi birçok dış faktörden etkilenmektedir. Bunlar, döviz fiyatlarındaki dalgalanmalar, mürekkebin kalitesi, türü, rengi ve satış fiyatları gibi faktörlerin yanı sıra mevsimsel veya siyasi değişikliklerde zaman serisini etkilemektedir. Buna göre girdi ve çlktı katmanları zaman serisini Şekil 4'te gösterildiği gibi bölümlendirilmiş olan altı adet veri grubunun her birisi için oluşmaktadır (xt-12, $\mathrm{xt}-24 \ldots \mathrm{t}-\mathrm{k})$.

Ağın eğitimi ve sinir ağının geri yayılım algoritmasının uygulanmasından sonra, YSA modeli Çizelge 2' de görüldüğü gibi MAPE ve RMSE değerleri elde edilmiştir.

\section{Çizelge 2. YSA Modeli}

\begin{tabular}{|c|c|c|c|c|c|}
\hline $\begin{array}{c}\text { Kullanılan } \\
\text { Zaman } \\
\text { Serisi }\end{array}$ & $\begin{array}{c}\text { Giriş } \\
\text { Katmanındaki } \\
\text { Nöron Sayısı }\end{array}$ & $\begin{array}{c}\text { Gizli } \\
\text { Katman } \\
\text { Sayısı }\end{array}$ & $\begin{array}{c}\text { Çııış } \\
\text { Katmanı }\end{array}$ & $\begin{array}{c}\text { MAPE } \\
(\%)\end{array}$ & RMSE \\
\hline YSA & 5 & 5 & 1 & 0.061 & 1.283 \\
\hline
\end{tabular}

Çizelge 2 incelendiğinde, YSA (5.5.1) modelinde bir giriș katmanı, bir gizli katman ve bir çıkış katmanı bulunduğu görülmektedir. Giriş katmanında beș, gizli katmanda beș, çıkış katmanında ise bir nöron bulunmaktadır.

Cizelge $3^{\prime}$ te yazıcı sarf malzemeler satıșlarının öngörüsü için kullanılacak olan en uygun modelin belirlenmesi amaciyla Irak Cumhuriyeti'nin farklı illerinde gerçekleşen yazıcı sarf malzeme satış verileri için kullanılan metotlardan elde edilen RMSE, MAE ve MAPE değerlerinin öngörü doğruluğu gösterilmektedir.

Çizelge 3. Box-Jenkins Metodu ile YSA Metodunun Öngörü Doğruluğu Ölçütlerinin Karșılaștırılması

\begin{tabular}{|l|c|c|c|}
\hline \multicolumn{1}{|c|}{ Model } & MAE & RMSE & MAPE \\
\hline ARIMA(0,1,0) $(0,0,1)$ & 64.99551 & 65.10048 & 9.481377 \\
\hline YSA(5.5.1) & 19.05708 & 22.89402 & 2.97907 \\
\hline
\end{tabular}

Çizelge 3' te görüldüğü üzere RMSE, MAE, MAPE değerlerinin öngörü doğruluğu ölçütüne dayalı olarak yapılan karşıllaştırmada YSA (5.5.1) sinir ağı modelinin değeri daha düșük olduğundan, ARIMA $(0,1,0)(0,0,1)$ modelinden daha üstün olduğu görülmüştür. Dolayısıyla en uygun tahminler için daha elverişli olan model YSA (5.5.1) sinir ağı modelidir.

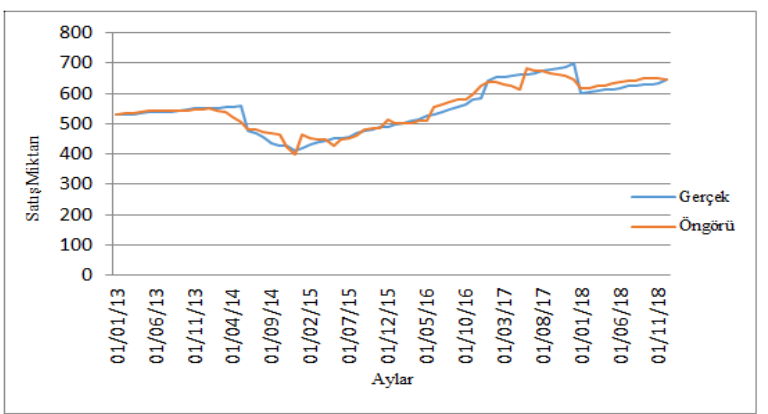

Şekil 5. YSA (5.5.1) Modelin Gerçek ve Tahmini Değerleri 
Şekil 5'te modelin gerçek ve tahmini değerleri arasındaki benzerlik görülmektedir.

Öngörüde bulunmak, modern analiz yöntemlerinden olan zaman serilerinin en son aşamasıdır. $\mathrm{Bu}$ aşamada YSA ile B-J modellerinin arasından en uygun olanın seçildiğine emin olunması gerekir. MAPE ölçütünün en düşük değerini bulmak için YSA (5.5.1) modeli kullanılmış ve Ocak 2019 ile Aralık 2020 ayları arası 24 adet değer için öngörüde bulunulmuştur. Öngörüde bulunulan 24 adet sonucu daha önceden bilgi sahibi olunan (fiilen gerçekleşmiş) sonuçlarla karşılaştırıldığında Çizelge 6'da yer alan sonuçlar elde edilmiştir. Burada 2020 yılındaki tahminleri, yazıcı sarf malzemeleri satışlarının miktarında bir iyileşme olduğunu göstermektedir. Bu durum altta yer alan Çizelge 4'de verilmektedir.

\section{Çizelge 4. YSA (5.5.1) Modeli Öngörü Değerleri}

\begin{tabular}{|c|c|c|c|c|}
\hline \multirow{2}{*}{ Aylar } & \multicolumn{2}{|c|}{ Gerçek Veriler } & \multicolumn{2}{c|}{ Öngörüler Veriler } \\
\cline { 2 - 5 } & $\begin{array}{c}2017 \\
\text { Değerleri }\end{array}$ & $\begin{array}{c}2018 \\
\text { Değerleri }\end{array}$ & $\begin{array}{c}2019 \\
\text { Değerleri }\end{array}$ & $\begin{array}{c}2020 \\
\text { Değerleri }\end{array}$ \\
\hline Ocak & 602 & 641 & 638.18 & 616.31 \\
\hline Şubat & 606 & 655 & 637.33 & 615.54 \\
\hline Mart & 610 & 653 & 627.86 & 624.14 \\
\hline Nisan & 613 & 658 & 625.66 & 625.42 \\
\hline Mayıs & 614 & 662 & 612.41 & 635.67 \\
\hline Haziran & 616 & 664 & 685.23 & 638.91 \\
\hline Temmuz & 624 & 668 & 676.54 & 640.38 \\
\hline Ağustos & 626 & 673 & 674.88 & 643.22 \\
\hline Eylül & 629 & 677 & 667.76 & 648.15 \\
\hline Ekim & 630 & 682 & 662.5 & 650.61 \\
\hline Kasım & 634 & 689 & 656.6 & 650.16 \\
\hline Aralık & 647 & 698 & 644.49 & 646.53 \\
\hline
\end{tabular}

\section{Tartışma ve Sonuç}

Hızla yenilenmekte olan bir çevrenin değişen ve gelişen bilgi çağında; etkin, hızlı ve sürekli iyileştirmeler gerekmektedir. Bu nedenle kurumların bu değişken ortama uyum sağlayabilmeleri şarttır. Bu sebeple gelecekteki satış miktarlarını öngörmek için en uygun modelin olușturulması faydalı olacaktır. Bu çalışmada iki adet istatiksel model kullanılmış olup, bunların birincisi ARIMA ikincisi ise YSA modelidir. Böylece zaman serisi yöntemlerinden, ARIMA ve YSA yöntemleri, öngörü doğruluklarını karşılaştırarak en yüksek doğruluğu sağlayan yöntem ve modelin belirlenmesinde etkili olmuştur.

Belirlenen model yardımıyla 2008-2018 yılları için Irak' taki yazıcı sarf malzemelerin satış miktarını ay itibariyle tahmin edilmesi amaçlanmıştır. Yazıcı sarf malzeme satışları zaman serisi, varyans ve ortalama yönleri açısından durağan olmayan bir seridir. Aylık durağan zaman serileri için gerekli olan öngörüde bulunmaya uygun bir modelin elde edilmesi için ister girdi isterse gizli katmanlar olsun çok katmanlı modellere ihtiyaç vardır. Çalışmanın sonunda, yazıcı sarf malzemeler satışlarının tanımı ve tahmini için
YSA (5.5.1), B-J yöntemlerinden biri olan SARIMA (Seasonal ARIMA) $(0,1,0)(0,0,1)$ modeline göre daha uygun olduğu saptanmıştır.

Yazıcı sarf malzemeler için, ileriye yönelik şirket üretimi, pazarlama, işletme yönetimi gibi konulara daha fazla önem vermesinin ve geliştirmesinin yanı sıra satış miktarlarının artırılması için de pazarlama konusunda yeni yöntemlerin geliştirmesi gerekmektedir. Gelecekte, yapılacak çalışmalar için; farklı mimarilere sahip YSA modelleri kullanılarak, tahmin çalışmaları önerilebilir. Öngörü metotları arasında en uygun olanını belirlemek amacıyla yeni tahmin testlerinin yapılması, bu amaçla B-J yöntemi ile YSA yöntemi karışımı olan homojen bir metot kullanılması önerilebilir.

Tahmin için kullanılan bu çalışmadaki model; Garg vd. [6], Safi [16], çalışmasıyla benzerlik gösterirken, Gao vd. [7], Nury vd. [14] çalışmasıyla farklılaşmaktadır. Çalışmada en uygun modelin, B-J yöntemi olduğu görülmektedir. Bunun nedeni, B-J modelinin doğrusal veriye sahip olan modellerde kullanılmasıdır. Doğrusal olmayan verilerde ise doğru sonuç her zaman alınamamaktadır.

Çalışma sonuçlarından da görüleceği üzere, tüm durumlar için uygun özel bir tahmin yöntemi yoktur. Verinin durumuna bakllarak en uygun modelin seçilmesi ve sonucunda da gerekli kontrollerin yapılması önemlidir. Bazı durumlarda birden fazla yöntemin birlikte kullanılması doğruluk oranını arttıracaktır.

\section{Kaynakça}

[1] Akdağ, M., 2015. Box Jenkins ve Yapay Sinir Ağı Modelleri ile Enflasyon Tahmini, Atatürk Üniversitesi, Fen Bilimleri Enstitüsü, Endüstri Mühendisliği Anabilim Dall, Yüksek Lisans Tezi, Erzurum.

[2] Bluestone, H., 1963. The Cycles in Broilers. Poultry and Egg Situation, USDA ERS PES-226 (1963): 13-18.

[3] Cancela, A., 2008. Comparative Study of Artificial Neural Network and Box Jenkins Arima for Stock Price Indexes, ISCTE Business School, Mastering Data Analysis Prospecting.

[4] Commandeur, J.J.F., and Koopman, S.J., 2007. Introduction to State Space Time Series Analysis.

[5] Çuhadar, M., 2006. Turizm Sektöründe Talep Tahmini İçin Yapay Sinir Ağları Kullanımı ve Diğer Yöntemlerle Karşlaştırmalı Analizi, Süleyman Demirel Üniversitesi Sosyal Bilimler Enstitüsü, Isparta. 
[6] Garg, N., Sharma, M.K., Parmar, K.S., Soni, K., Singh, R.K., and Maji, S., 2016. Comparison of ARIMA and ANN Approaches in Time-Series Predictions of Traffic Noise, Noise Control Engineering Journal, Vol. 64, No. 4, pp:522-531.

[7] Gao, G., Lo, K., and Fan, F.L., 2017. Comparison of ARIMA and ANN Models used in Electricity Price Forecasting for Power Market. Energy and Power Engineering, University of Strathclyde, Glasgow, UK, No. 9. pp. 120-126.

[8] Gerra, M.J., 1959. The Demand, Supply, and Price Structure for Eggs. US Dept. of Agriculture.

[9] Hamzaçebi, C., and Fevzi, K., 2004. Yapay Sinir Ağları ile Türkiye Elektrik Enerjisi Tüketiminin 2010 Yılına Kadar Tahmini. Gazi Üniversitesi Mühendislik-Mimarlık Fakültesi Dergisi 19.3.

[10] Ighravwe, D., Anyaeche, C., 2019. A Comparison of ARIMA and ANN Techniques in Predicting Port Productivity and Berth Effectiveness. International Journal of Data and Network Science, Vol. 3, pp. 13-22.

[11] Karaboga, D., and Bahriye, A., 2007. Artificial Bee Colony $(\mathrm{ABC})$ Algorithm on Training Artificial Neural Networks. Signal Processing and Communications Applications, 2007. SIU 2007. IEEE 15th. IEEE.

[12] Leuthold, R.M., et al., 1970. Forecasting Daily Hog Prices and Quantities: A study of Alternative Forecasting Techniques. Journal of The American Statistical Association, 65.329: 90-107.

[13] Montanes, E., Quevedo, J.R., Prieto, M.M., and Menéndez, C.O., 2002. Forecasting Time Series Combining Machine Learning and Box-Jenkins Time Series Advances in Artificial IntelligenceIberamia 2002 (pp. 491-499): Springer.

[14] Nury, A., Hasan, K., and Alam, J., 2017. Comparative Study of Wavelet-ARIMA and Wavelet-ANN Models for Temperature Time Series Data in Northeastern Bangladesh, Journal of King Saud University-Science, Vol. 29, PP. 4761.

[15] Pandey, V., 2019. Predictive Efficiency of ARIMA and ANN Models: A Case Analysis of Nifty Fifty in Indian Stock Market. International Journal of Applied Engineering Research, Vol. 14, No 2, pp. 232-244.

[16] Safi, S., 2016. A Comparison of Artificial Neural Network and Time Series Models for Forecasting GDP in Palestine. American Journal of Theoretical and Applied Statistics, Vol. 5, No. 2, pp. 58-63.
[17] Suits, D.B., 1962. Forecasting and Analysis with an Econometric Model. The American Economic Review 52.1.

[18] Schmitz, A., and Donald, G.W., 1970. Forecasting Wheat Yields: An Application of Parametric Time Series Modeling. American Journal of Agricultural Economics, 52.2: 247-254.

[19] Tobin, B.F., and Arthur, H.B., 1964. Dynamics of Adjustment in The Broiler Industry, Dynamics of Adjustment in The Broiler Industry.

[20] Ture, M., and Kurt, I., 2006. Comparison of Four Different Time Series Methods to Forecast Hepatitis A Virus Infection. Expert Systems with Applications, 31(1), 41-46.

[21] Anderson, T.W., 1971. The Statistical Analysis of Time Series, John Wiley and Sons, Inc, New York.

[22] Box, G., and Jenkins, G., 1976. Time Series Analysis Forecasting and Control San Francisco Helden-Day.

[23] Ameen, B.H., 2005. Using Neural Networks in Estimating Time Series by Applying Electric Power Consumption in Mosul City, Master Thesis, Mosul University, Iraq.

[24] Pirece, A.D., 1971. Least Squares Estimation in the Regression Model with Autoregression Moving Average Errors, Biomatrika, vol 58, P (299- 321) .

[25] Sharawei, S., 2005. An Introduction to Modern Time Series Analysis, King Abdulaziz University, Saudi Arabia, 1st edition.

[26] Aljubouri, W.D.S., 2010. Predicting the Inflation Level in Monthly Consumer Prices in Iraq Using Binary Variable Time Series, "Master Thesis, College of Administration and Economics, AlMustansiriya University, Iraq.

[27] Krose, B., and Smagt, V.D.P., 1996. An Introduction to Neural Networks, Eighth Edition. The University of Amsterdam, pp 33-34. 